\title{
Robotization of Logistics Processes
}

\author{
Nikoleta Mikušová ${ }^{1, *}$, Zdeněk Čujan ${ }^{2}$, and Eva Tomková ${ }^{1}$ \\ ${ }^{1}$ Technical University of Košice, BERG Faculty, Logistics Department, Park Komenského 14, 04001 \\ Košice, Slovakia \\ ${ }^{2}$ College of Logistics, Přerov, Palackého 1381/25, 75002 Přerov, Czech Republic
}

\begin{abstract}
Recently, it is possible to register a relatively large increase of robotized workplaces also in the fields which not suppose the using of robots. Their implementation was limited due to complexity of work activities, including for example handling of various goods in large quantities in various combinations and often also in the limited space.
\end{abstract}

\section{Introduction}

Industrial robots were until recently immobile and non-intelligent machines, respectively their task was repeating of simple repetitive tasks with the high level of accuracy. These abilities are sufficient for simple production processes but they are not sufficient for most logistics activities. In logistics, the requirements for industrial robots are much higher. Robots in logistics have to have a distinctive ability in a variety of goods, must be able to distinguish various parts in an infinite number of combinations, must be able to perceive their surroundings, move and interact with the environment and work with people. Increasing flexibility and lower cost of robotized workplaces create prerequisites for their use in logistics activities such as order picking, packing and shipping, as well as deliveries. In the field of logistics $80 \%$ is still manually operated. Problems of unfavourable demographic developments and the associated declining number of employees can be replaced by robotic workplaces in some logistics activities.

\section{Relationship among human, robotization and mechanization}

For humans, it is significant that compared to the current simple mechanization and using control technology (IT technologies), it excels with its natural intelligence and functional mobility - from kinematics we express the mobility by the number of degrees of freedom. The human hand has among shoulder joint and at the end of one of the fingers 110 degrees of freedom. If we take into account all fingers, we will get 270 freedoms. It is obvious (Fig. 1), that the mutual comparison of the level of human intelligence, but especially its physical (power, speed) and functional (mobility) capabilities with the capabilities of industrial robots and manipulators, is significantly higher in these automation devices. A robot is an automated or computer-controlled integrated system, capable of autonomous, targetoriented interaction with the natural environment according to human instructions [1]. This

*Corresponding author: nikoleta.mikusova@tuke.sk 
interaction is based on the perception and recognition of this environment and manipulation with objects, or in moving in this environment [2]. The basis for the construction of robots and manipulators are mechanisms, i.e. mechanical devices that serve to transform of movement and transfer of forces and provide displacement of the objects (tools, etc.) in a way, that results from the required function of the system [3]. This function is for example technology of the logistics process. Mechanisms of robots and manipulators are formed by the set of moveably connected members, one moves and one creates a frame. These mechanisms are derived from opened spatial kinematic chains which contain binary members. Members are bound together by kinematic couples.

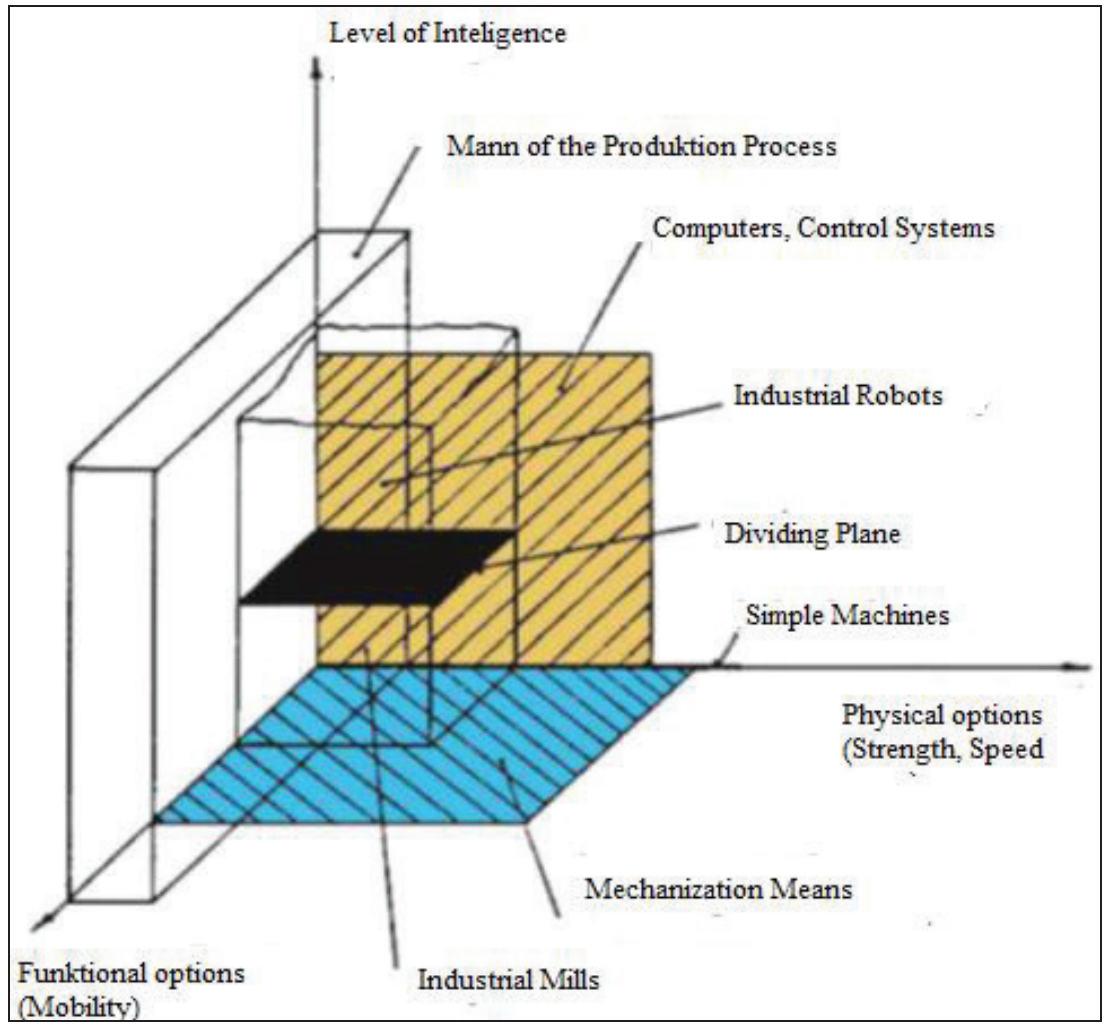

Fig. 1. Interaction among human and machine. Source: [2]

\section{Basic kinematic construction of robots (positioning)}

The mechanical construction of the industrial robot is created by movement system that is usually divided into two separate parts:

- the first part is the main movement system which provides positioning of the centre of gravity of the object in the space (positioning system) and

- the second part is presented by accessory movement system (orientation system) which determines displacement - orientation of the object in the space [4].

The orientation system often extends also the function of the main positioning system and it is structurally concentrated in a subgroup that is referred as the wrist. At the output of the whole movement system is located the working head adapted to the way of handler or robots for realization of handling, or other technological operations. 
The positioning device with 10, 20 or 30 degrees of freedom is joined to the robotic positioning device. Technological head is joined to the orienteering device. The total number of degrees of freedom is different, from 40, 50, 60 and more. An angular kinematic structure with a torus (torus is created by rotation of the circle around the axis) by the spatial workplace is currently the most widespread in the construction of universal robots which have within the frame of the wrist two or three rotational movements.

\section{Robotization in intra-logistics}

Robots find application by loading and unloading of semi-trailers, or containers. At present, robots are able to analyse different sizes of shipments and subsequently optimize operation of loading or unloading of the goods. Development of new generation of intelligent robots also accelerates progress in the areas of scanning technology, faster computer technologies, analysis of data, accumulators, clouds utilization and thus greater flexibility. The use of new technologies extends the ability of apply and use of robots in their quantity and their individual species. Dozens of robotics specialists in the world develop solutions for more complex warehouse works. Robots facilitating this work have various functions and forms. From chassis automatically transport small shelves to warehouse staff, mobile carts that follow the warehouse employee, and also mobile robotic arms that can pick simple items from racks. Automated warehouses are usually designed for store of pallets and boxes or crates.

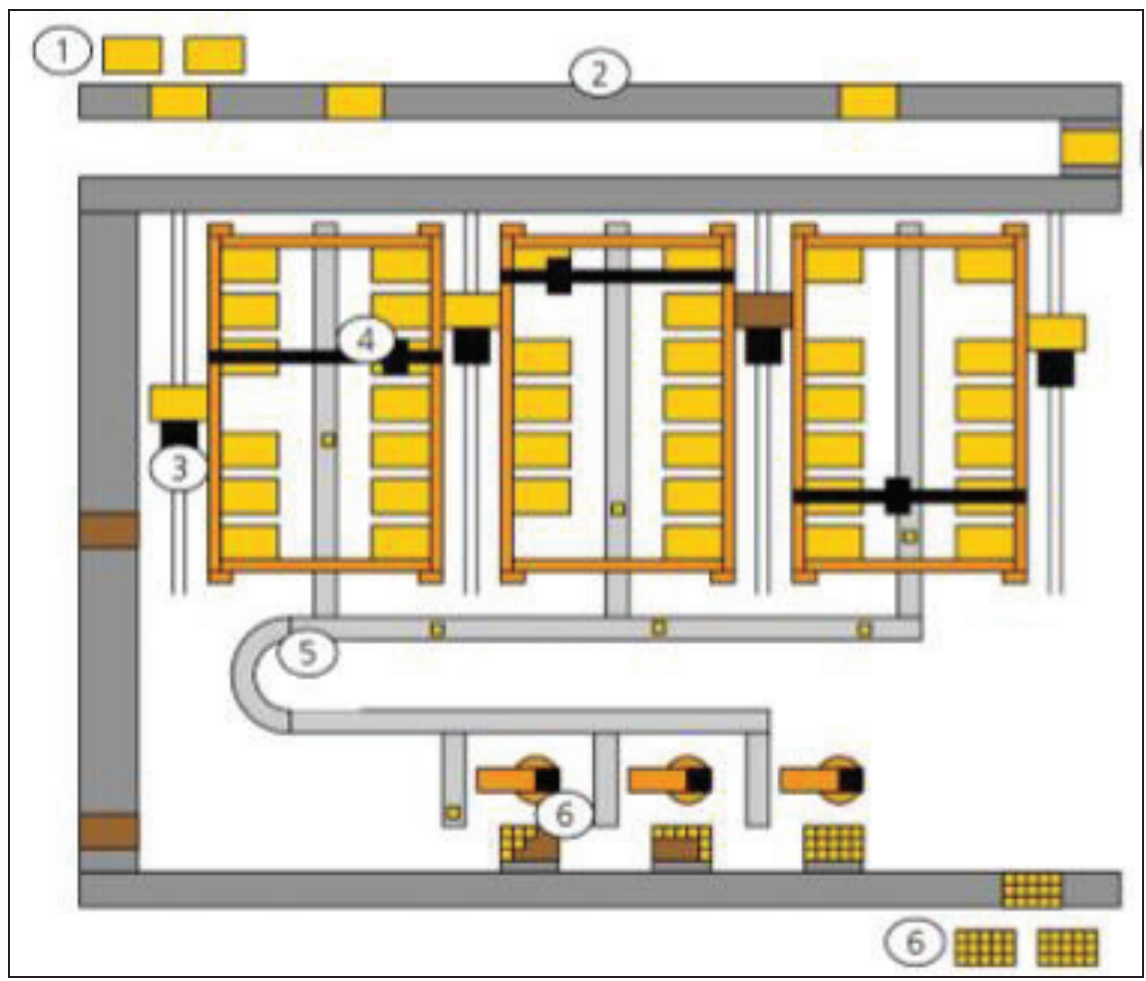

Fig. 2. Layout of automated storehouse. Source: [5]

Warehouses working in automatic mode are designed in a way that minimizes the need for human factor. Their conception, data management, overview and order in warehouse and storage processes are mainly designed to eliminate errors by storage that are often 
caused by a human factor. By realization of automatization and robotization of logistics activities in a warehouse (storage, packaging), all mechanically controlled processes, control operations are under the management of the control system . Therefore, the time for storage or removing of pallets is shortened. Shortening of storage operations is by realization of automatization and robotization is up to a third against classically controlled warehouse.

The pallets with goods (Fig. 2) are at the entry (1) placed on the conveyor belt (2), from which they are stored by automatic collator (3). The height collator can operate in fully automatic mode, in long-distance or local semi-automatic mode. By manipulation with pallets the portal handler (4) is used, and this stores the pallets to the belt conveyor (5). Conveyor transfers pallets to the robotized workplace (6), with the process of depalletization. Goods are transfer to completion according to the the customer's order [5].

The pallets with goods (see Fig. 3) are at the entry (1) located on the conveyor belt (2), from which the goods on the pallets are taken by the collator (3) and stored to the shelf system. Depalletization is performed on robotic workplaces (5), where the pallets with goods are moved by a belt conveyor (4). Classification of goods is realized manually at the workplace (7) after removal from the conveyor (6).

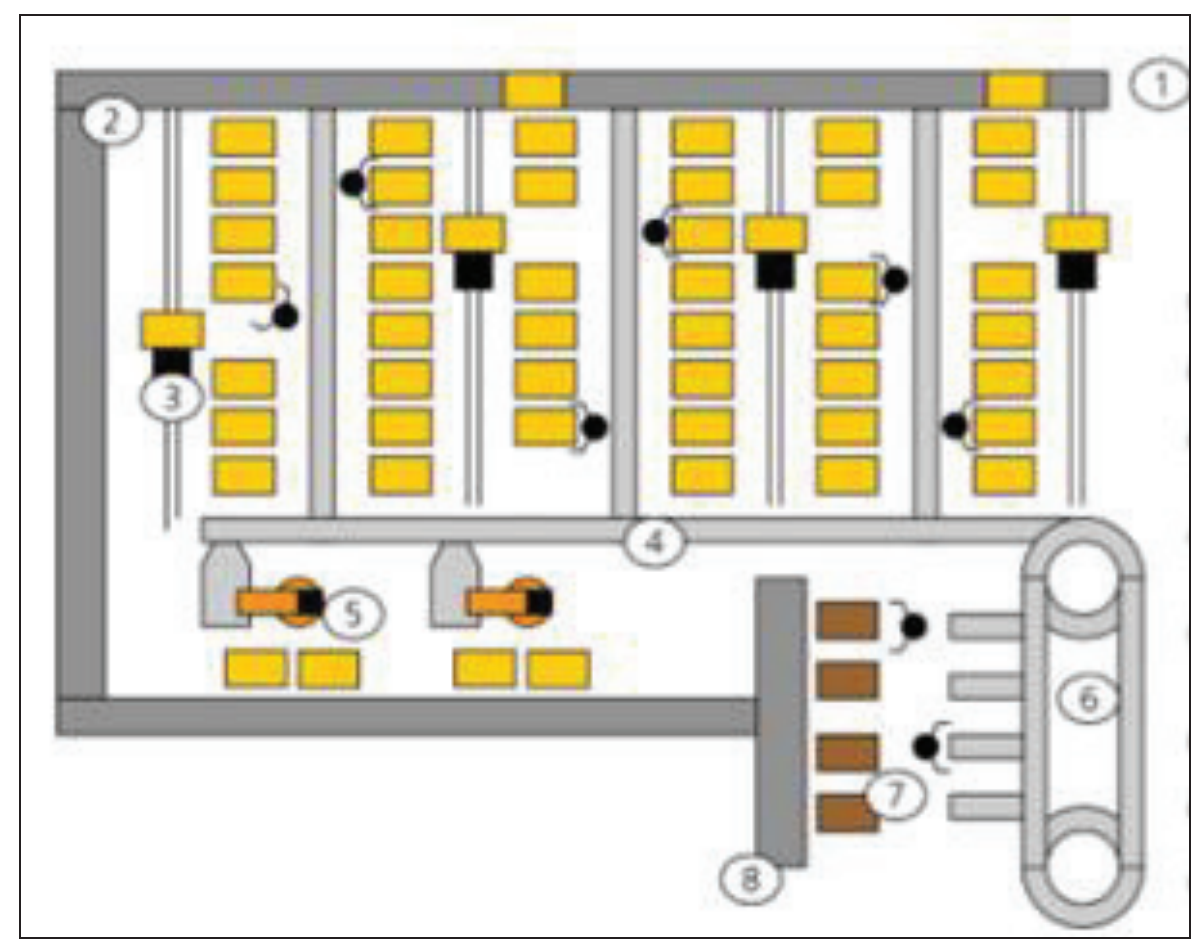

Fig. 3. Scheme of automatic and manual handling with goods. Source: [5]

For enterprises which have only globally determined aims of logistics development and provide bigger flows, it is strategically advantageous to orientate investments to automated technologies [6]. In practice, it usually means gradual building of a larger automated system [7] (Fig. 4). 


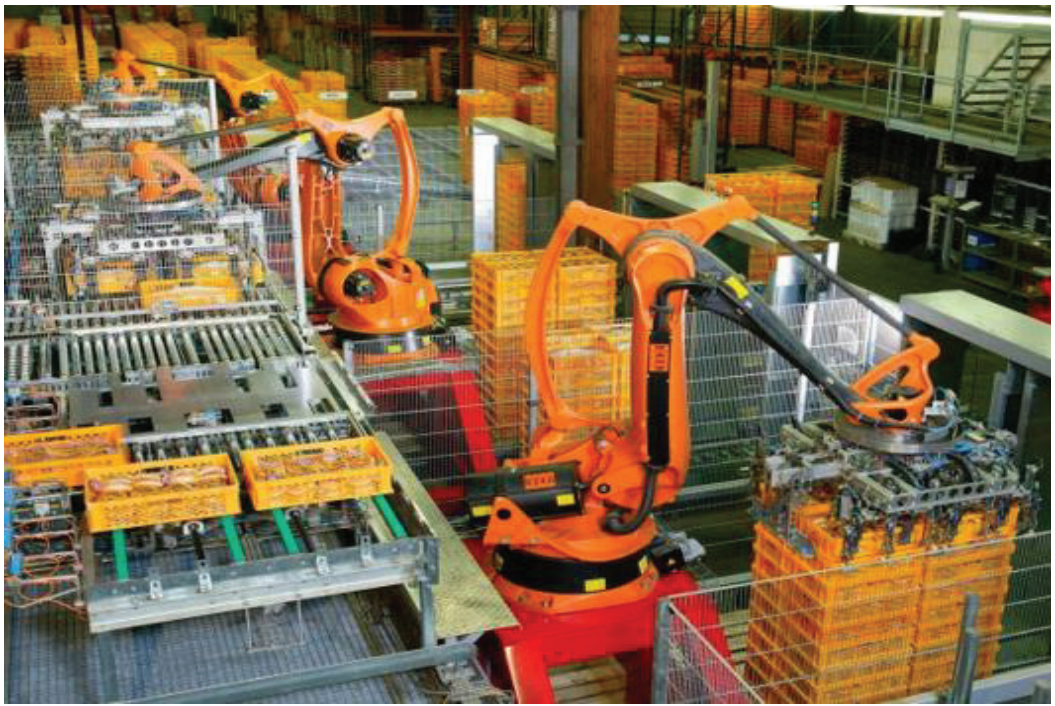

Fig. 4. Robotized workplace in logistics centre. Source: [8]

\section{Robotization of production and assembly line}

Development of robotization of production lines (Fig. 5) is not dependent only on the possibilities of the relevant technical means, but it is also influenced by the development of its own technologies [9]. Development and realization of technologies can be expected in flexible systems created by multifunctional production machines and robots.

Fully automatic operation of production machines, equipment and system cannot be imagined without automatic manipulation, which in the most cases directly determined the automated operation of technological means.

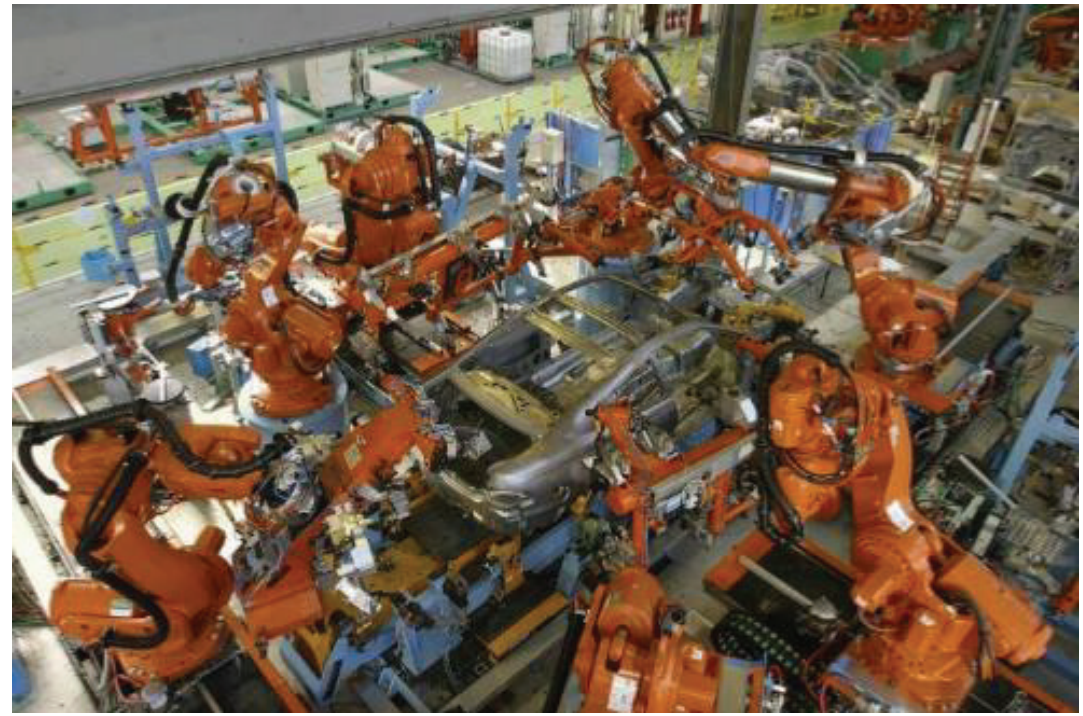

Fig. 5. Robotized welding workplace of car body. Source: [10]

The structure of the elementary technological workplace is formed by production mean for the realization of one technology, input and output hopper of objects for processing, 
manipulator of object, hopper of tools and handler of tools. Various variants of the workplace layout are based on a different level of integration of constructional solution of these partial functional parts. By connection of these elements of elemental technological workplace by automatic transport or handling means, it is created an automatic production system (Fig. 6).

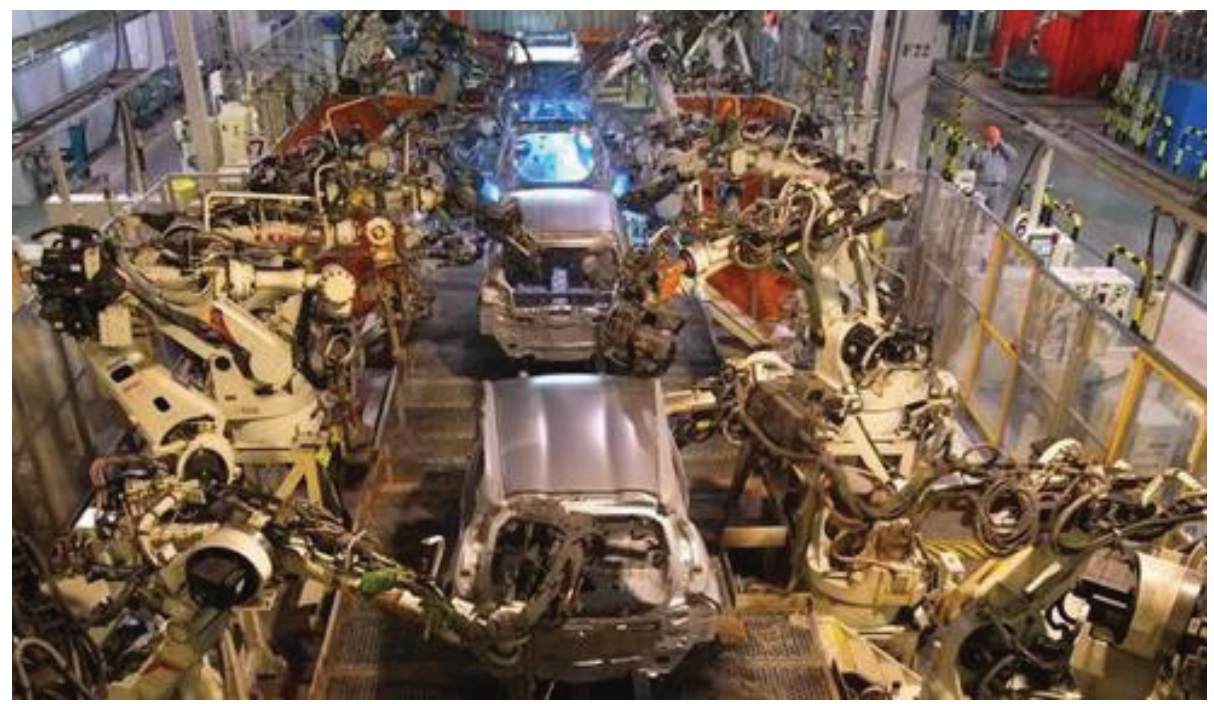

Fig. 6. Robotized welding line of car bodies. Source: [10]

Trend in the development of automated production and assembly workplace is affected by the necessary minimization of transport and handling operations. The minimization of these activities influences the direction of development of new production machines and equipment, including transport and handling equipment (Fig. 7).

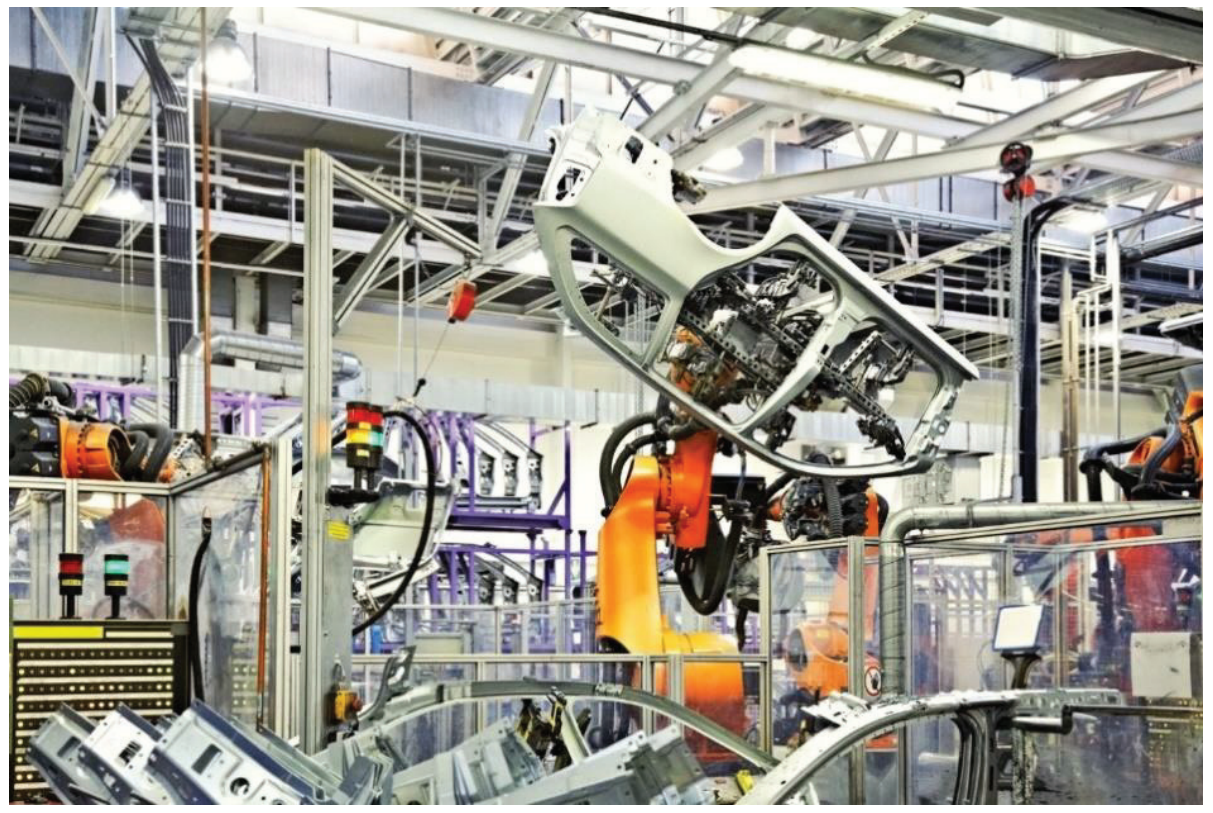

Fig. 7. Robotized assembling of car bodies parts. Source: [10] 


\section{Robotization of transport, transfer and handling means}

Material handling and its transport in production enterprises is one of the moments effecting the total costs for production of the product [11]. Reducing production costs in the areas that can be influenced by the use of new technologies and organization of work is one of the ways how to reach the chosen goal.

Reducing of the rate of live work in routine, and also difficult activities, that are periodically repeated is the easiest by the use of robot handler, unmanned vehicles and robots, too. This fact is presented in production enterprises by using of transport routes by material processing, from material receiving to store, transport of semi-finished products among operators, then storing of the final product in the warehouse and its allocation by sale.

AGV - Automated Guided Vehicles (Fig. 8) - are used for material handling and they serve in a variety of applications with autonomous operation of logistics systems without human intervention [12]. The advantage of this solution is above all that there is no need to set a road/way because the vehicle can ride directly on the floor, if it fulfils certain criteria, such as flatness, continuity, small inclination and other parameters, determined by producer as conditions for trouble-free operation [13]. This means that this system is flexible and its rebuilding, or extension is very easy [14]. The most common concept of this vehicles contains one guided, and at the same time driven wheel, or axle with two wheels and the other wheels are supportive [15].

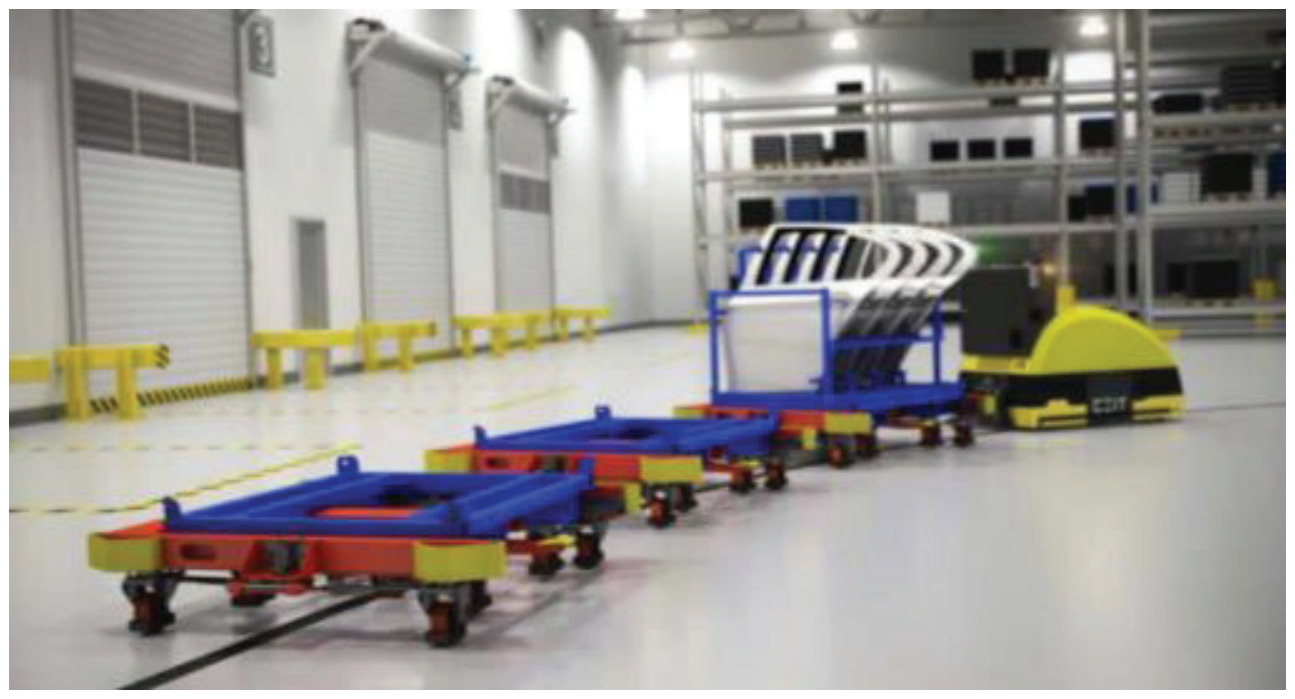

Fig. 8. Intelligent hoisting set CEIT. Source: [16]

Vehicles can be guided by several ways which always have their pro-and-con. Selection of suitable navigation is good to consult with a producer, with experiences about application for different environments and requirements $[17,18]$.

\section{Conclusion}

Lack of labour power is currently the biggest motivation for implementation of automatized production lines and robotic workplaces. At present, lack of labour power is a very strong motivation for greater implementation and use of robots and by this way to achieve the needed increasing of productivity and meet customer requirements. By effective use of 
robots and robotized workplace, robots are four to six times more efficient than human service. But the latest robot solutions are fully automated and often they are combined with human service (for example material completion), it brings automatized systems for reducing of handling costs by 20 to $40 \%$. These values depend on many factors, such as complexity with order processing and technical preparation of production, order size, production and storage capacity, etc.

This work is a part of these projects VEGA 1/0063/16, KEGA 018TUKE-4/2016.

This paper is supported by the research project "From horse-drawn railway to intermodal transport" within Visegrad Fund.

\section{References}

1. H. Neradilova, G. Fedorko, 12th international scientific conference of young scientists on sustainable, modern and safe transport, 638-643 (Procedia Engineering 192, Elsevier science BV, Amsterdam, 2017)

2. J. Skařupa, Průmyslové roboty a manipulátory (TU Ostrava, Czech Republic, 2012)

3. V. Molnar, K. Pacutova, ICTTE 2016 - Proceedings of the third international conference on traffic and transport engineering, 570-575 (Belgrade, Serbia, 2016)

4. R. Konflíček, Roboty a pružné výrobni systémy (VUT Brno, Czech Republic, 2012

5. D. Fritsch, K. Wöltze, Logistik. wt Werkstatttechnik on line, 96, 624 (2006)

6. J. Fabianova, P. Kacmary, V. Molnar, P. Michalik, Open Engineering 6, 270-279 (2016)

7. L. Bartuska, O. Stopka, Chovancova, J. Lizbetin, Transport Means - 19th International Conference on Transport Means, 107-111 (Kaunas University of Technology, 2016)

8. Průmyslové roboty a manipulátory, Available online: http://www.kod.tul.cz/predmety/AOV/Vyuka/prednaska_robot.pdf (2017)

9. J. Strohmandl, UPB Sci. Bull. Ser. D Mech. Eng. 76, 223-230 (2014)

10. Robot, Available http://www.mmspektrum.com/multimedia/image/87/8701.jpg (2017)

online:

11. I. Kubasakova, O. Stopka, R. Kampf, Communications: scientific letters of the University of Žilina 2, 9-13 (2014)

12. H. Neradilova, G. Fedorko, Open Engineering 6, 700-710 (2016)

13. A. Kuptcova, P. Průša, G. Fedorko, V. Molnár, Transport Problems 11, 21-31 (2016)

14. O. Kodym, ICCC -13th International Carpathian Control Conference, 296-299 (High Tatras, Podbanské, Grand Hotel Permon, Slovak Republic, 2012)

15. R. Danel, V. Kohut, O. Kodym, M. Repka, V. Kebo, M. Kijonka, SGEM 2013 - 13th International Multidisciplinary Scientific Conference, 151-158 (Albena, Bulgaria, 2013)

16. Z. Čujan, 3. vědecká konference pro doktorandy (College of Logistics, Přerov, Czech Republic, 2017)

17. Z. Čujan, Logistika výrobních technologii (College of Logistics, Přerov, Czech Republic, 2013)

18. R. Kampf, L. Lizbetinova, K. Tislerova, Open Engineering 7, 26-30 (2017) 